\title{
BIO-ENERGY PRODUCTION FROM EXOTIC SPECIES AND SYNCHRONIZED CONSERVATION OF NATIVE BIODIVERSITY
}

\author{
Vinod Haridas \\ Department of Botany, TKMM College, Nangiarkulangara, Kerala.
}

\begin{abstract}
A survey was conducted to identify the level of awareness among people regarding problems caused by invasive exotic weeds to our biodiversity and sense to use the same productively. Biogas is increasingly being used as an alternate cooking fuel in selected areas of urban and semi-urban Alappuzha during 2014-15. Apart from survey visits, mass awareness programmes were also conducted to convey the potential and significance of usage of exotic weeds like Eichhornia for producing biogas at house hold level to deal with the twin issues that we face today ie. fuel depletion and rapid reduction of indigenous biodiversity.

The present study so far hints to the truth that the people of the current generation are severely over reliant on the fossil fuel, LPG. It was found in the survey that use of aquatic invasive weeds as major raw materials for biogas plants are not encouraged or implemented in each and every household. It is only because of the lack of understanding of importance of biodiversity conservation by the authorities concerned. In addition to production of green energy, roughly about two crores can be saved in revenue because that much amount is presently being spent for the ineffective efforts of removal of the weeds from our water bodies, every year. Such measures are described here as futile because the removed quantum of weeds make a come back with double the vigor in another three months of sunshine. After analyzing survey reports we suggest that, dried exotic weeds must be made available at affordable rates to individual households.

The greatest advantage of making use of exotic plant weeds as potential and constant source of bio energy is that inadvertently we are making way for the native biodiversity to flourish through. Besides we shall be able to extend our LPG cylinder for an extra month or two. This means not only energy savings but also sustainable use of undesirable vegetation on a long term basis. Such measures may not only help in accruing huge indirect monitory savings but also the awareness thus gained by citizens on biodiversity conservation can then be focused for understanding of natural ecosystems in a better way.
\end{abstract}

Keywords: Bio-energy production, biodiversity.

\section{INTRODUCTION}

Biogas is unique in several aspects when compared to its alternate fuel counterparts. The commendable factor that makes biogas unique is that its substrate is not only absolutely free (kitchen waste and faeces) but also something that we always wanted to get rid off, the bio-waste. So installing a biogas plant naturally becomes two birds in one shot' type of achievement. Probing further we come across the positive facts that it is non-explosive, non smoky flame, regulatable just like an LPG stove, tank available at subsidized rate, almost repair free, portable, no complicated technology, flame strength equivalent to that of LPG, one hour flame guaranteed for every 3 to $4 \mathrm{~kg}$ biowaste per day, space requirement not more than a normal water tank, any non-fibre and non-acidic biowaste can be raw material etc. Biogas is one of the most economical ways to cook or light a home in rural areas of the world when other power sources are unavailable.
Apart from guaranteed features, it has added benefits too. One of the added advantages of a biogas facility is that the unspent slurry is a rich source of nitrogen rich manure for vegetable crops. Since cow dung is required only during the initial stage; user is free from the menace of cattle breeding. Moreover, unpleasant odour of dung lasts for the first 3 or 4 months only. Another advantage revealed from our study is that the bio-energy tank in continuous use was found to retain its activity even after keeping idle for up to four months. This means the nuclear family who own an active biogas tank can go for anguish free holidays for months together! The greatest advantage for a budget family is that along with doing away with garbage, they are now able to save their LPG cylinder for an extra month or two. This means savings not only for them but the whole nation. Now in real quantitative terms let us see what the savings is in Indian rupee. Suppose you are a person using 8 LPG cylinders per 
year. By using LPG it is reduced to 6. You straightly save approx. Rs. 800/- $(400 \times 2)$ for yourself and $600 /-(300 \times 2$ in terms of subsidy) for the nation. Just multiply with crores of citizens and we happily arrive at the magic of biogas in bringing national level savings to the tune of multicrores which can be diverted for better infra structure across the country which as a natural byproduct of biogas usage, would have already become almost garbage free too.

This being the crystal clear truth however, according surveys conducted by us during 2012 and 2015, initiative from the governing bodies could only increase the percentage of biogas users from 0.6 during 2010 to a meager 1.2 after a span of five years. At the same time households who wish to install a biogas tank in their premises has increased from 68 to 79 per cent.

Future prospects of this investigation suggest a modified version of biogas usage for urban users and flat dwellers which involve cultured vials of anaerobic methanogenic bacteria developed through research.

\subsection{Relevance of the study}

Biogas is one of the first programmes undertaken by Malanadu Development Society. No systematic evaluation of the programme has yet been made till date. There are also other biogas implementing agencies in the Governmental and Non-governmental sector. Comparative efficiency of these agencies needs to be evaluated. The study makes an attempt to enquire into the strengths and weaknesses in implementing the programme. Another relevance of the study is that biogas programme is popularly believed to have deeply influenced energy and agricultural sectors. This study provided an opportunity to verify the basis of such popular notion. Looking at biogas programme as an activity of local change, the study makes an effort to find out the options of replicability and scaling up of the biogas programme. It is hoped that the study will bring forth useful clues that can go a long way in improving agriculture in Kerala, especially in the highranges of Kerala. It gives MDS, other NGOs, Panchayaths and Research Institutions useful insights on sustainability, replicability and scaling up the programme and draw lessons from it for the whole of Kerala.

\subsection{Brief history of the Biogas Programme in India}

Biogas has a known history of slightly more than 100 years of application in India. The most prominent milestones in biogas extension in India are given below vide table 5 Table 5- Milestones in Biogas Development in India No Year Experiments, innovations and findings 11897 Bombay Experiment Ackworth Leper Home Matunga, Bombay; Biogas from septic tanks was used for lighting 21907 Ackworth Leper Home Matunga, Bombay; Operated an engine generator with biogas as well as gas used for cooking 31920 Calcutta Experiment. Dr Pal and Dr Ghosh of the University College of Scienceand Technology. Biogas produced from water hyacinth 41923 Waste materials like banana peals, leaves etc used as feed materials at the experiments conducted by Dr. Joshi and Dr. Fowler at Indian Institute of Science - Bangalore. 51937 IARI Experiment by Dr S.V Desai. Cow dung used for gas production 0.6cubic foot gas/pound of dung. The Dadar sewage purification plant based on biogas fermentation method set up at Bombay 6 1944-45 MrM.Renaudot's Experiment Cattle dung and agro waste digester produced 15-25 cum gas/day and compressed gas used to run Tractors. 71946 Indian Agriculture Research Institute designed the first family size biogas plant 81949 Mr Jashbai Patel Experiment with the development of the forerunner of the KVIC plant. Osmania University, Hyderabad Negotiable cover used as gasholder for the first time Input $=301 \mathrm{~kg}$ dung+30l litre water Capacity $=20 \mathrm{cubft}$ gas/day 91952 Development of the floating drum type biogas plant. It was named 'Grama Laxmi- III' by Jashbai Patel, a Gandhian worker from Gujarat. 10 1961 KVIC adopted biogas programme for dissemination, deciding to disseminate the model of Gramalakxmi-III. PRAD- Planning Research and Action Division (PRAD), a separate division under the UP State Planning Board sets up GGRS- Gobar Gas Research Station at Ajitmal in UP. 11 1963-64 KVIC began providing financial assistance to farmers in constructing biogas plants. This was a departure as it used to support only khadi institutions to construct biogas plants in the period 1961-63. 121967 KVIC completes 10,000 biogas plants 131974 60,000 plants completed. An impact assessment of biogas programme made and Government of India takes up implementation of biogas programme in right earnest. 141977 Janatha biogas plant with a fixed dome designed and constructed by GGRS, a wing of Planning Research and Action Division (PRAD) of UP State Planning Institute in their research station at Ajitmal in UP to overcome the disadvantages of the KVIC type floating drum model 151981 NPBD- National Project on Biogas Development launched by Government of India. 161982 DNES- Department of Non-conventional sources of Energy created under the Ministry of Energy - Government of India. NPBD 
brought under DNES. Biogas programme included in the 20 point programme of the Prime Minister. 17 1984 Deen bandhu biogas plant designed by AFPROAction for Food Production a Delhi based NGO. 18 1987 Government of India approves Deen Bandhu model Biogas Plants and extends subsidy benefit to it. 191992 DNES upgraded into a Ministry and named it as MNES

\section{STATUS OF FOSSIL FUEL}

Fossil fuels are fuels formed by natural process such as an aerobic decomposition of buried dead organisms .fossil fuels contain high percentage of carbon and include coal,petroleum and natural gas. It was estimated by the energy information administration that in 2007 primary sources of energy consisted of petroleum $36.0 \%$,coal $27.4 \%$,natural gas $23.0 \%$ amounting to an $86.4 \%$ share for natural fuels in primary energy consumption in the world

Non fossil sources in 2006 included hydro electric $6.3 \%$ nuclear $8.5 \%$ and others (geothermal,solar,tide,wind,wood,waste) amounting to $0.9 \%$ world energy consumption was growing about $2.3 \%$ per year.

Fossil fuels are non renewable resources because they take millions of years to form and reserves are being depleted much faster than new ones are being made the production and use of fossil fuels raise environmental concerns.a global movements towords the generation of renewable energy is there for under way to meet increase the energy needs.the burning of fossil fuels produces around 21.3 billion tones of $\mathrm{CO} 2$ per year ,but it is estimated that natural processes can only absorb about half of that amount,so there is a net increase of atmospheric $\mathrm{CO} 2$ per year .CO2 is one of the green house gases that contribute to global warming ,causing the average surface temperature of the earth to raise in response,which the vast majority of the climate scientists will agree will cause major adverse effects

\subsection{International Status}

In developing countries cookers /stoves,lamps,refrigerators are appliances commonly fuelled by biogas .biogas can be converted to electricity using fuel cell, through this is still considered a research area due to the need for very clean gas and the cost of cells. In contrast using biogas to fuel a compution engine and in turn an electric renerator is a proven means of producing electricity, given the wide availability of suitable generators. For example in India a well studiedcommuity bio gas digester was used to fuel a modified diesel engine and run an electrical renerator.

Biogas burns with a clean, blue flame and stoves have been considered the best means of exploiting biogas in rural areas of developing countries .

Worldwide, effective and wide spread implementation of domestic biogas technology has occurred in countries where governments have been involved in the subsidy, planning, design, construction, operation and maintenace of bio gas plants. There are several such contries in asia, where in particular china and India have seen massive campaigns to popularize the technology. Surveys in various regions of India have the proportion of functional plant to be from $40 \%$ to $81 \%$. It should be noted that although not always started, digester age is a significant factor in performance.

Up to half the UK's domestic gas heating could be met by turning waste into biogas , according to a report from National Grid. The report looks at how all the biodegradable waste streams such as sewage, food and wood could be turned into biogas and injected into the gas distribution system. At the moment there is a small quantity of production of biogas in the UK coming from land fill and sewage plants, but it is being used to generate electricity . The National Grid says these valuable waste resources could be used more efficiently by turning thenm into bioethane.This could meet $50 \%$ of the domestic gas needs and helps achieve renewable energy targets for 2020.

Compressed natural gas (CNG)as also biogas aare commercially used as vehicle fuel in New Zealand and Italy. Conversion kit for biogas fuelled vehicle is virtually the sme as for CNG which is marketed as an automotive fuel in many parts of the world these kits permitschange over form gas to liquids fuel and vice versa at a short notice .As methane is only half of the weight of the air, dispersal of the leaking gas is faster .This makes biogas as safer fuel than either LPG or Pertorl. Ibadan ,the second largest city in Nigeria is the center of a large agricultural region in Oyo state . since the $19^{\text {th }}$ century , fierce intertribal rivalries and other political unrest have pushed large influxes of refugee and military populations into the city. This chaotic growth has discouraged the kind of municipal infrastructure thatis taken for granded in the developed world.soon, however ibadan's power 
needs at least will get a boost from a relatively simple but extremley finding favour across Africa : biogas. theibadan plant will be one of the larger biogas installations in Africa

Bengladesh is endowed with plentiful supply of renewable sources of energy. Out of the various renewable sources, solar and biomass and to a limited extend, wind and hydropower are effectevleyused.the effective source of renewable energy is biomass.Under this category improved stoves,biogas plant and biomass briquetting are note worthy. According to an official estimates there is a cattle population of 24 million and poultry population of 75 million. This can produce about $3 \mathrm{~m}$ biogas. The Local Government Engineering Department (LGED)and IFRD are working to install the biogas plants in the $r$ ural areas.So far a total of 19,596 plants have been installed.

\subsection{National Status}

India's consumption of energy is expected to double in the near feature. The national advisory board for energy in India has published a report forecasting the required quantity and the manner for supply of energy in the feature. The boards estimate that India has enough resources to sustain 16-22 Mio small biogas plants with $2 \mathrm{~m}^{2}$ reactor volumes, each to supply sufficient energy for a farmer family with 4 cows

In plants in India, the substrate, cattle dung and biogenous waste, are manually mixed with water in a ratio of $10 \%$ dry matter to $90 \%$ water. The mix is filled in to the digester by simply pushing.The reactor is neither heaten not isolated ,enabling the fermentation process to take place at temperatures in the region of $14^{\circ} \mathrm{C}$ during winter and $25^{\circ} \mathrm{C}$ during summer.In the reactor itself, a substrate is mixed by a simple mixer which is operated manually. After a dwell time of the substrate in the reactor of around 100 days the fermented residues is removed with buckets or scoops.pumping systems are not used.In general, such a small biogas plant coast around 50000 Indian rupees per cubic meter of digester.The plants are constructed with the help of local artisans who receive a daily wage of 50 rupees.

The construction of more biogas plant has revealed several beneficial sideeffects.Such as a significant reduction in the exhaustive cultivation of forests.Unexpected success were noted in medical sector also .Since respiratory systems and eyes were no longer exposed to aggressive wood smoke fromefire,the number of cases of acute asthma and eye diseases was significantly reduced (Dieter Deublein and Angelika Steinhauser).

A metropolitan city like Calcutta daily accumulates 2000 tonnes of garbage which can be converted into biogas. $12 \mathrm{~kg}$ of garbage produces 30 liters of methane gas in a mini mint.The coast of the plant is 3 lakhs production is still on an experimental basis. Daily $500 \mathrm{~kg}$ of garbage will produce 300 liters if methane. Mathene may be used as cooking gas or to genarate electricity or can be transformed into alcohol.

Biogas from the glue industry wastes is thought in India. For various reasons the Biogas plant programme has not yet gained great momentum in India. One of the reasons is the lack of requisite quantity of cattle dung.

Ther are a number of goshalas, dairies,and village communities having Large number of cattle, which have the potential for installing biogas enrichment and bottling system. In urban areas large quantity of biogas can be produced in sewage treatment plants using an aerobic digestion. The Okhlm sewage treatment plant in New Delhi is an example where more than 10000 cubic meters of biogas is prodused every day. Due to rising cost of petroleum products and environmental concerns it has become imperative to make use of local resourcesas an altrnate to petroleum fules. Therefore it is worldwide trend to explore and make use of biogas as an alternat fuel (Biogas-enrichment and bottling technology for vehicular use, Dr:Virendrakumarvijay)

SolankiVijanbhaiMaldebhai runs a small milk processing plant in Junagadha district of Gujarat, buying and processing about 200 litres of milk daily. Processing of milk leaves a foul smelling liquid which is dificult to dispose. This was at time when AKRSP was trying to motivate people in village to motivate biogas plant. This innovative farmer who had adequate cattle decided to install and run a biogas plant on dairy waste. He apporached AKRSP staff and after some initial hestation, a biogas plant was constructed, which is operating completely on dairy waste. It take care of the cooking fuel needs and more importantly, helps him to dispose the foul smelling dairy waste in hygienic way (Biogas-The Indian NGO Experience, Somadutta et al.)

Biogas technology has been use in India for nearly a hundred years. However its dissemination began in a concreted manner only in 1981 with the launching of the National Project on Biogas Development (NPBD), and its subsiquentincluions in 
the Primr Ministers Twenty -Point Programme. It further gained momentem with the 3 establishment of the Department (now Ministry) of Non conventional Energy sources (MNES) in 1982.

The Minister adopted a decentrelized multi agency and multi model implimentationstategy for NPBD. At the state level programme is implimented through the nodal agency(Council for Science technology, Energy Development agency etc.) which is primarly responsible for achievingtargets, managing finances, monitering etc. other agencies involved in the implimentation at the district level and below are several government bodies such as District Rural Development Agency (DRDA), Block Development Office(BDO) local enterpreneurs, ruralnanogovernmental organizations (NGOs), gramapanjayath, dailycooperatives, etc.Further the National banks are also involved in the programme by providing soft loans to beneficiaries to partially meet the coast of construction.

To provide support to the implementation of NPBD, the ministry has created a network of 17 Regional Biogas and Training Centers (RBDTCs) across the country. These centers impart training and provide technical support to various groups of people involved in the implementation process. MNE has also setup an eight regional offices which provide guidance to the state nodal agencies and monitor the progress of the programme (Somadutta et al., 2006)

Significant regional variations were observed in the fuel consumption levels across the country. The choice and level of use of particular fuel is governed primarily by its access to woody biomass. This in turn is determined by factors like local climate, vegetation type etc.

\section{TYPES OF BIOGAS PLANTS}

\subsection{Brick Tanks}

Tanks can be built from clay bricks. When preparing the ground for the tanks, the base must be particularly well rammed. For the base plant the following materials are applicable.

- Quarry stones with cement mortar filling and screed

- $\quad$ Brick work with screed or concrete

Bricking of curved bowl is simple. One needs only a center. E.g.: from a heap of stone, which is removed afterwards, and a radius stick. In contrast to this, concreting is more difficult because a flame work is necessary.
Brick work and mortar: Mortar and bricks should have about the same strength. Bricks of low quality require thicker walls.

Mortar for brickwork consists of sand, water and binding agents. Cement as binding results in smooth elastic mortar. In order to get good water proof brick work, a mixture of cement and lime should be used as binding agent. The sand for bioreactor brick work must be finally sieved. It must be clean and should not contain loam, dust, or organic components.

\subsection{Reinforced concrete tanks}

The reinforced concrete must be free of cracks and resistant under the special conditions during fermentation over the entire period of utilization.

With reinforced concrete, the acidic substrate, can penetrate to the reinforcement and corrode if $\mathrm{CO}_{2}$ containing air also penetrates to the reinforcement. $\mathrm{CO}_{2}$ converts calcium hydroxide in the concrete to calcium carbonate. The $\mathrm{pH}$ value in the concrete around the reinforcement's decreases to values below 9 and the steel begins to corrode.

In order to prevent such damage, the local laws stipulate a quality supervised concrete with high resistance to strong chemical attack when the concrete is exposed to $\mathrm{pH}$ value below 4.5 over longer periods. The parts of structure can consist of water - repellent concrete with high frost resistance.

\subsection{Tanks of normal steel metals with enamel layer or plastic coating}

An enamel layer protects the entire steel surface durably. It is glass like and extremely resistant.

Such tanks are completely pre fabricated from steel sheet segments. For enameling, the segments are prepared in different dipping baths. ie., cleaned, derusted etc. Then the enamel powder is blown on in an even layer, in the klin (the heart of an enamel factory), the powder coated single metal is heated up to $860^{\circ} \mathrm{C}$ so that enamel powder melts and forms a strong bond with the surface of a metal. The single metal sheets are connected together by means of special screws. Such tanks are easy, fast and safe to construct.

\subsection{Tanks of stainless steel}

Stainless steel tanks usually consist of welded stainless steel of the quality 1.4301, 1.4404, $1.4436,1.4435,1.4571$, but they are occasionally 
built from stainless steel plates screwed in to a steel structure made up of hot galvanized profiles. The plate segments are sealed to each other with methane - gas tight elastic PU sealing bands. Screws, nut etc have to be made from stainless steel.

According to the elastic requirements, such tanks have either curved covers or flat covers with appropriate stiffening. In the latter case a static proof has to be adduced.

\subsection{Fixed type biogas plants}

In fixed type biogas plants which first developed in China, gas is stored in the upper part of the digester. In this design there is no separate gasholder and upper portion of the digester pit itself acts as gasholder. Displaced level of slurry provides requisite pressure for release of gas for its subsequent use. The plant works on both plant waste and animal waste materials and is convenient work within both continuous and batch mode. Normally animal wastes are fed daily whereas residues are fed in batches. As the plants does not involves any steel parts and it can be built with local materials, its construction costs are low and operation cost virtually nill. Beingunderground, space needs are also minimal Materials like lime clay, lime - concrete, concrete, bricks, stones etc can be used for plant construction.

Based on Chinese design, Gobar Gas Research station developed the first ever fixed dome biogas plant in India in 1922 which was come to be known as Janata plant. It involves an underground cylindrical digester and a hemi spherical dome but without man hole cover. The dome is fitted with a GI pipe through which the biogas is taken out. It is made of bricks, cement and concrete. Following construction, digester walls and dome are cured for several days for imparting requisite strength to the plant.

\subsection{Movable 'drum' type plant}

It basically comprises an underground brick masonary digester connected with an inlet and outlet and covered by a movable steel gasholder for gas collection. Gas holder moves up and down guided by a central guide pipe depending upon accumulation and discharge of gas. Movable gasholder made of mild steel alone accounts for some $40 \%$ of the total plant cost and accordingly these plants are much more expensive than fixed dome type. Maintenance costs of these plants are also high in view of much the need to paint gasholder every year to prevent corrosion. Based on series of chronological developments in India, JARI and KVIC developed two plant designs which have come to be known as the IARI and KVIC models.

\section{7. 'Deenabandhu' biogas plant}

Action for food production (AFPRO) an NGO in 1984 developed a low cost fixed dome plant called Deenabandhu model meaning friend of the poor. It ia appropriate for using all types of wastes and minimizes biogas losses from inlet chamber and ensures maximum utilization of digester volume there by making the plant operates at designed HRT. $\mathrm{t}$ is $30 \%$ cheaper than Janata model. Storage capacity is $33 \%$ of daily gas production. It has curved bottom and a hemispherical top which are joined at their bases with no cylindrical portion in between. Displaced slurry following fermentation moves to the outlet displacement chamber as there is no displacement space on the inlet side. An inlet pipe connects mixing tank with the digester.

Cattle dung slurry prepared in 1:1 ratio with water is fed up to the level of second step in the outlet tank which is also the base of the outlet displacement chamber. As the gas generates and accumulates in the empty portion of the plant, it presses the slurry of the digester and displaces it into outlet chamber it starts rising. This fall and rise continuous till the level in the digester reaches the upper end of the outlet opening, and at this stage the slurry level in the outlet tank reaches the height of discharge opening. Any unused gas beyond this stage escapes through the outlet tank.

\section{8. 'GAYATRI' MODEL}

Gayatri model was developed by Govt: implements factory Bhubaneswar. It eliminates the use of brick dome; a pre- fabricated fiber glass reinforced plastic (FRP) dome of the same dimension is used for gas collection.

\section{9. 'TNAU' Model}

Tamil Nadu agricultural university at Coimbatore evolved 4 the designs of biogas plants with a view to achieve among other reduction in retention period. One of its model is similar to the fixed dome plant of the Janata type with a flat bottom where as the other model resembles the Nepalese version of the Chinese model with curved digester bottom and Ferro-cement dome. Special feature of the plant is low retention period of 15 days which is achieved by periodic addition of microorganism which speed up the digestion process. 


\subsection{0. 'KRISHNA' biogas plant}

The plant consists of a digester with its dome and lower cylindrical portion cast monolithically in reinforced cement concrete (RCC). The inner surface of the structure that comes in contact with biogas under varying pressure is coated with an epoxy paint to prevent possible gas leakage. In addition a single compensatory slurry displacement tank also cast in RCC is provided over the dome to account for increase in gas pressure. The coast of the Krishna model is lower than the KVIC model.

It is possible to connect a latrine unit to the biogas plant so that night soil could be digested along with the cattle dung.

\subsection{1. 'MANIPAL' model}

This model has features of both Indian and chinese models. It has a rectangular digester with an inclined RCC roof. There is no separate gasholder unlike in earlier Indian designs and larger inclined space above the slurry level provides storage area for resulting biogas to accumulate. Digester can be built particularly inside or fully above ground depending uponground conditions variation in pressure is achieved a shallow ferro-cement cover dipped in water seal on sloping roof slabs. Intlet pipes are selected according to the feed material availability and desired mode of plant operation. Resulting biogas is taken out with the help of a pipe. 